\title{
4-Aminopyridine inhibits the neuromuscular effects of nitric oxide and 8-Br-cGMP
}

R.N. Queiroz ${ }^{2}$,

E.R.P. Ramos ${ }^{1}$ and W. Alves-Do-Prado ${ }^{1}$
Departamentos de ${ }^{1}$ Farmácia e Farmacologia and ${ }^{2}$ Medicina, Centro de Ciências da Saúde, Universidade Estadual de Maringá, Maringá, PR, Brasil

\section{Correspondence}

W. Alves-Do-Prado

Laboratório de Farmacologia

da Transmissão Neuromuscular DFF, UEM

Av. Colombo, 5790

87020-900 Maringá, PR

Brasil

Fax: +55-44-225-3863

E-mail: alvesprado@wnet.com.bror

waprado@dff.uem.br

Research supported by $\mathrm{CNPq}$

(No. 521727/96).

Received March 8, 2002

Accepted March 28, 2003

\section{Abstract}

The effects induced by nitric oxide (NO) in different tissues depend on direct and/or indirect interactions with $\mathrm{K}^{+}$channels. The indirect interaction of $\mathrm{NO}$ is produced by activation of guanylyl cyclase which increases the intracellular cGMP. Since NO, cGMP and 4-aminopyridine alone induce tetanic fade and increase amplitude of muscular contractions in isolated rat neuromuscular preparations, the present study was undertaken to determine whether or not the neuromuscular effects of $\mathrm{NO}$ and 8 -Br-cGMP can be modified by 4-aminopyridine. Using the phrenic nerve and diaphragm muscle isolated from male Wistar rats (200-250 g), we observed that L-arginine $(4.7 \mathrm{mM})$ and 8 -Br-cGMP $(18 \mu \mathrm{M})$, in contrast to D-arginine, induced an increase in the amplitude of muscle contraction $(10.5 \pm 0.7 \%, \mathrm{~N}=10$ and $8.0 \pm$ $0.7 \%, \mathrm{~N}=10)$ and tetanic fade $(15 \pm 2.0 \%, \mathrm{~N}=8$ and $11.6 \pm 1.7 \%$, $\mathrm{N}=8)$ at 0.2 and $50 \mathrm{~Hz}$, respectively. $\mathrm{N}^{\mathrm{G}}$-nitro-L-arginine $(4 \mathrm{mM}$, $\mathrm{N}=8$ and $8 \mathrm{mM}, \mathrm{N}=8)$ antagonized the effects of L-arginine. 4-Aminopyridine ( 1 and $10 \mu \mathrm{M})$ caused a dose-dependent increase in the amplitude of muscle contraction $(15 \pm 1.8 \%, \mathrm{~N}=9$ and $40 \pm 3.1 \%$, $\mathrm{N}=10)$ and tetanic fade $(17.7 \pm 3.3 \%, \mathrm{~N}=8$ and $37.4 \pm 1.3 \%, \mathrm{~N}=8)$. 4-Aminopyridine $(1 \mu \mathrm{M}, \mathrm{N}=8)$ did not cause any change in muscle contraction amplitude or tetanic fade of preparations previously paralyzed with $d$-tubocurarine or stimulated directly. The effects induced by 4 -aminopyridine alone were similar to those observed when the drug was administered in combination with $\mathrm{L}$-arginine or 8-Br-cGMP. The data suggest that the blockage of $\mathrm{K}^{+}$channels produced by 4-aminopyridine inhibits the neuromuscular effects induced by NO and 8-Br-cGMP. Therefore, the presynaptic effects induced by NO seem to depend on indirect interactions with $\mathrm{K}^{+}$channels.
Key words

- L-arginine

- Nitric oxide

- cGMP

- Skeletal muscle

- Tetanic fade

- $\mathrm{K}^{+}$channel 
Nitric oxide (NO) is synthesized by NO synthase (NOS) (1) and its biological effects are mediated by direct interaction with ion channels or by activation of the guanylyl cyclase-cGMP pathway (2). NO directly activates $\mathrm{Ca}^{2+}$-dependent $\mathrm{K}^{+}$channels of high conductance (100-250 pS) in vascular smooth muscle cells (3) and a $\mathrm{Ca}^{2+}$-dependent $\mathrm{K}^{+}$ channel of low conductance (10-14 pS) in the gastric fundus of rats (4). Conversely, $\mathrm{NO}$ inhibits $\mathrm{Ca}^{2+}$-activated high and low conductance $\mathrm{K}^{+}$channels in postganglionic neurons of avian culture ciliary ganglia. This effect is independent of the action of NO on $\mathrm{Ca}^{2+}$ channels (5).

NOS is present in the sarcolemma of type II fibers of rat skeletal muscle (6) and in motor nerve endings (7). NOS is a stereospecific enzyme that metabolizes L-arginine without metabolizing D-arginine under similar experimental conditions (8). NOS activity is inhibited by $\mathrm{N}^{\mathrm{G}}$-nitro-L-arginine (LNOARG), an L-arginine analogue (9). The effects of endogenous NO (from L-arginine) are pharmacologically similar to those induced by NO released from an exogenous source such as 3-morpholinosydnonimine (SIN-1) or S-nitroso-N-acetylpenicillamine (9).

Acting at the presynaptic level, the NO precursor L-arginine (4.7-9.4 $\mathrm{mM}$ ) produces a dose-dependent increase in muscle contraction amplitude in rat neuromuscular preparations which have been indirectly stimulated at $0.2 \mathrm{~Hz}(10)$. In contrast, acting on skeletal muscle, it reduces the amplitude of muscle contractions in preparations previously paralyzed with $d$-tubocurarine and directly stimulated at $0.2 \mathrm{~Hz}(10)$. The presynaptic action of NO reduces the effect produced by its postsynaptic action by activation of the guanylyl cyclase-cGMP pathway (10). The action of the NO precursor Larginine (4.7 to $9.4 \mathrm{mM}$ ) or SIN-1 at the presynaptic level produces a dose-dependent increase in tetanic fade when the nerve is receiving stimulation at a high rate (11). In contrast, L-arginine and SIN-1 reduce the maximal tetanic tension (postsynaptic action) when a high stimulation frequency is applied directly to diaphragm preparations previously treated with $d$-tubocurarine (11). The presynaptic and postsynaptic effects of NO were also observed in assays performed at high frequency with superoxide dismutase, a selective scavenger of superoxide anion radicals $(11,12)$. Since the NO-induced neuromuscular effects may depend on a direct and/or indirect interaction with $\mathrm{K}^{+}$channels, the present study was undertaken to determine the neuromuscular effects of the NO precursor L-arginine and of 8-Br-cGMP on the rat phrenic nerve diaphragm preparation previously treated with a $\mathrm{K}^{+}$channel blocker.

Phrenic nerve and diaphragm muscle was isolated from male Wistar rats (200-250 g) and assembled according to the method described by Bülbring (13). Each muscle was immersed in a 20-ml chamber containing Krebs buffer (188 mM NaCl, $47 \mathrm{mM} \mathrm{KCl}$, $1.9 \mathrm{mM} \mathrm{CaCl}_{2}, 1.2 \mathrm{mM} \mathrm{MgSO}_{4}, 25 \mathrm{mM}$ $\mathrm{NaHCO}_{3}, 1.2 \mathrm{mM} \mathrm{KH} \mathrm{KO}_{4}$, and $11 \mathrm{mM}$ glucose) at $37^{\circ} \mathrm{C}$ and continuously aerated with a mixture of oxygen (95\%) and carbon dioxide $(5 \%)$. The phrenic nerve was stimulated by a supramaximal rectangular pulse $(0.2 \mathrm{~Hz}, 0.05 \mathrm{~ms})$ from a bipolar platinum electrode. Muscle contractions were recorded with a Ugo Basile polygraph (Varese, Italy). Although in some experiments the standard rate of stimulation was $0.2 \mathrm{~Hz}$, tetanic stimulation $(50 \mathrm{~Hz})$ was applied to the nerve for $10 \mathrm{~s}$ at $15-\mathrm{min}$ intervals. The tension produced at the beginning of tetanic stimulation (A) was compared with that obtained at the end (B) (Figure 1). L-arginine, D-arginine and 8-Br-cGMP (Sigma, St. Louis, MO, USA) were then added to the organ bath, and a $50-\mathrm{Hz}$ frequency was repeated at $t=5$ and $20 \mathrm{~min}$. The same sequence was repeated with 4-aminopyridine (RBI, Natick, MA, USA) added 5 min prior to L-arginine or 8 Br-cGMP. The time (20 min) when the drugs 
produced maximal effects was determined and taken as a parameter for data comparison. The ratio obtained after drug addition was taken to be the percent of that observed before drug administration.

Data were submitted to ANOVA followed by the Bonferroni test, with the level of significance set at $\mathrm{P}<0.05$. A similar experimental design was used when the neuromuscular preparations previously paralyzed with $d$-tubocurarine were stimulated directly.

In agreement with the literature $(10,12)$, L-arginine $(4.7 \mathrm{mM})$ induced an increase in the amplitude of muscle contraction and tetanic fade when the muscle was stimulated indirectly at 0.2 and $50 \mathrm{~Hz}$, respectively (Figure 2). These effects had their origin at the presynaptic level, as previously shown in similar studies $(10,11)$. In other words, Larginine reduces muscle contraction amplitude at $0.2 \mathrm{~Hz}$ and maximal tetanic tension at a high stimulation rate in preparations previously paralyzed with $d$-tubocurarine and directly stimulated $(10,11)$. D-arginine did not produce any change in the amplitude of

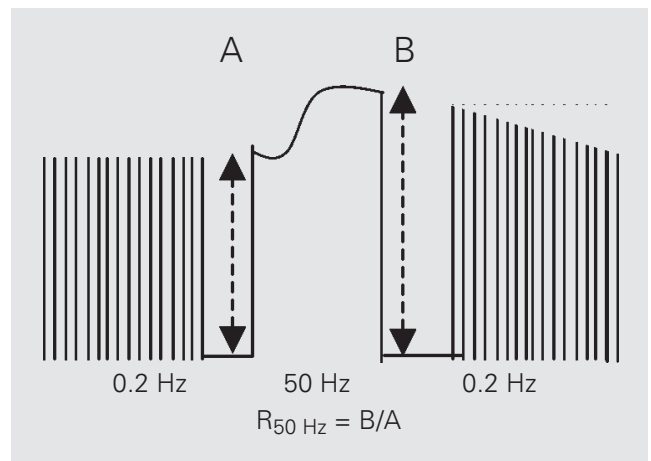

Figure 1. Diagrammatic representation of muscle contraction recorded at $50 \mathrm{~Hz}$. The effects of the drugs are calculated as the ratio $(R)$ between tension at the end $(\mathrm{B})$ and maximal tension at the start $(A)(R=B / A)$ of indirect stimulation. The sensitivity of the recording system was lower at $50 \mathrm{~Hz}$ than at $0.2 \mathrm{~Hz}$.
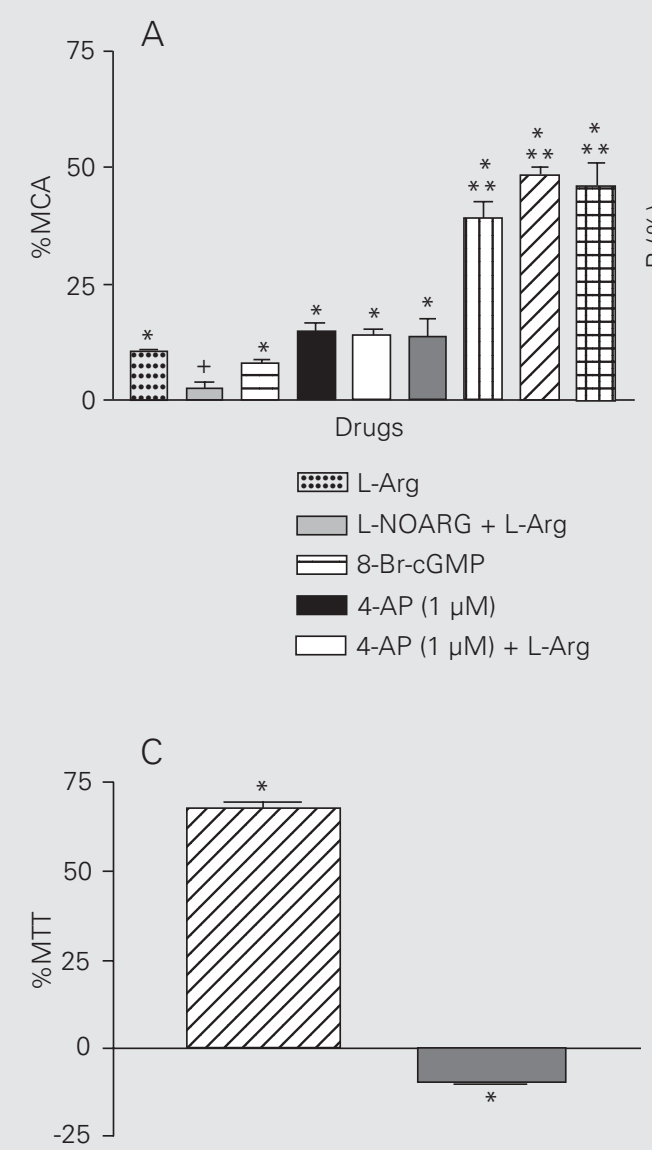

$E Z$ Indirect

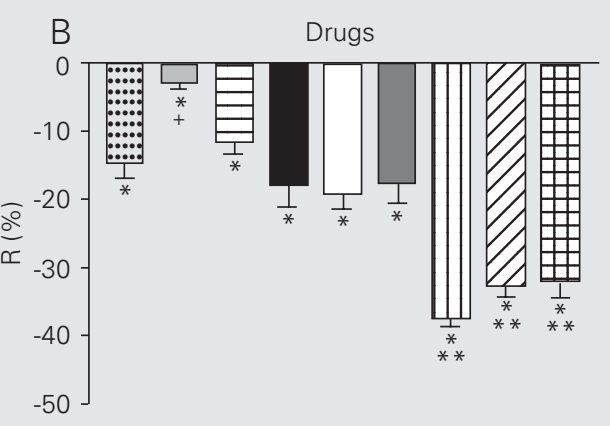

4-AP $(1 \mu \mathrm{M})+8-\mathrm{Br}-\mathrm{cGMP}$

एس 4-AP $(10 \mu \mathrm{M})$

R7 4-AP $(10 \mu \mathrm{M})+\mathrm{L}-\mathrm{Arg}$

\#丑 4-AP $(10 \mu \mathrm{M})+8-B r-c G M P$

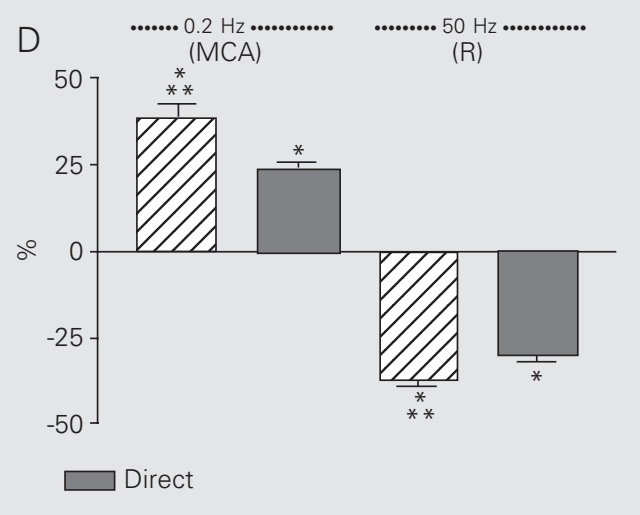

Figure 2. Increase of muscle contraction amplitude (\% MCA) and reduction of ratio $(R)$ values induced by $4.7 \mathrm{mM}$ L-arginine (L-Arg), $18 \mu \mathrm{M}$ 8-Br-cGMP and 1 and $10 \mu \mathrm{M}$ 4-aminopyridine (4-AP) in rat neuromuscular preparations indirectly stimulated at $0.2(\mathrm{~A})$ and $50 \mathrm{~Hz}$ (B). Antagonism by $\mathrm{NG}^{\mathrm{G}}$-nitro-L-arginine (LNOARG) of the increase in MCA and of the reduction in $R$ values induced by L-Arg (L-NOARG + $\mathrm{L}-\mathrm{Arg}$ ) is also shown ( $\mathrm{A}$ and $\mathrm{B}$ ). $C$ shows the percent increase or reduction in maximal tetanic tension (MTT) induced by $10 \mu \mathrm{M}$ 4-AP in indirectly or directly stimulated neuromuscular preparations. The percent increase in MCA and reduction in $\mathrm{R}$ values induced by 4-AP in preparations indirectly and directly stimulated at 0.2 and $50 \mathrm{~Hz}$ (D) are also recorded. Column height represents the mean \pm SEM of 8 to 10 experiments. ${ }^{*} \mathrm{P}<0.05$ compared to control (drug-free Krebs buffer; ANOVA); * *P<0.05 compared to other agents; $+P<0.05$ compared to L-Arg in the absence of L-NOARG (Bonferroni post hoc test). 
muscle contractions at $0.2 \mathrm{~Hz}$ or in tetanic fade at $50 \mathrm{~Hz}$ (data not shown). On the other hand, previous treatment of the preparations with L-NOARG (4 and $8 \mathrm{mM}$ ) according to Refs. $10-12$ and 14 antagonized both the increase in the amplitude of muscle contraction and tetanic fade induced by L-arginine (Figure 2).

Therefore, we propose that the effects of L-arginine depend on its metabolism by NOS to produce NO, thereby acting on motor nerve endings (14). Furthermore, current research shows that 8 -Br-cGMP $(18 \mu \mathrm{M})$ induced effects similar to L-arginine (Figure 2 ). This suggests that the effects of $\mathrm{NO}$ are mediated by activation of guanylyl cyclase. This hypothesis is supported by results from similar studies showing that ODQ, a guanylyl cyclase blocker, antagonizes the effects induced by NO in neuromuscular preparations of cats or rats $(11,14)$.

4-Aminopyridine ( 1 and $10 \mu \mathrm{M})$, in agreement with a previous report (15), induced a dose-dependent increase in the amplitude of muscle contraction at $0.2 \mathrm{~Hz}$ and of tetanic fade at $50 \mathrm{~Hz}$ in indirectly stimulated preparations (Figure 2). However, these effects were lower with $10 \mu \mathrm{M} 4$-aminopyridine in preparations paralyzed with $d$-tubocurarine and stimulated directly. On the other hand, $1 \mu \mathrm{M} 4$-aminopyridine did not increase the amplitude of muscle contraction or of the tetanic fade in preparations previously paralyzed with $d$-tubocurarine or stimulated directly (data not shown). These results sug- gest that $1 \mu \mathrm{M} 4$-aminopyridine seems to act only at the presynaptic level, while $10 \mu \mathrm{M}$ 4-aminopyridine apparently interacts with pre- and postsynaptic sites. The presynaptic effects of $10 \mu \mathrm{M} 4$-aminopyridine reduced its action on skeletal muscle.

NO inhibits $\mathrm{Ca}^{2+}$-activated $\mathrm{K}^{+}$channels of large and small conductance in postganglionic neurons of avian culture ciliary ganglia. This effect is independent of $\mathrm{NO}$ action on $\mathrm{Ca}^{2+}$ channels (5). Furthermore, it has been shown that $\mathrm{NO}$ activates or blocks $\mathrm{Na}^{+}$ channels in motor nerve endings (16-19). On the other hand, it has also been shown that $\mathrm{NO}$, either directly or via cGMP, activates $\mathrm{K}^{+}$channels in vascular smooth muscle cells $(3,20)$. L-arginine and 8-Br-cGMP added to the bath 5 min after $1 \mu \mathrm{M} 4$-aminopyridine induced effects similar to those observed with 4-aminopyridine alone. Since agents acting in combination at different sites to produce similar results are expected to induce higher effects than those obtained from each agent alone, the results suggest that the blockage of $\mathrm{K}^{+}$channels produced by 4aminopyridine impairs the presynaptic effects induced by NO and 8-Br-cGMP. Therefore, the presynaptic effects induced by NO seem to depend on indirect blockage of $\mathrm{K}^{+}$ channels produced by cGMP.

\section{Acknowledgments}

We are grateful to Mrs. I.L. Santos for technical support.

\section{References}

1. Mayer B, Schmidt K, Humbert P \& Bohme E (1989). Biosynthesis of endothelium-derived relaxing factor: a cytosolic enzyme in porcine aortic endothelial cells $\mathrm{Ca}^{2+}$-dependently converts L-arginine into an activator of soluble guanylyl cyclase. Biochemical and Biophysical Research Communications, 164: 678-685.

2. Fagni $L$ \& Bockaert J (1996). Effects of nitric oxide on glutamategated channels and other ionic channels. Journal of Chemical Neuroanatomy, 10: 231-240.

3. Bolotina VM, Najibi S, Palacino JJ, Pagano PJ \& Cohen RA (1994). Nitric oxide directly activates calcium-dependent potassium channels in vascular smooth muscle. Nature, 368: 850-853.
4. Kitamura K, Lian Q, Carl A \& Kuriayama H (1993). S-nitrosocysteine, but not sodium nitroprusside, produces apamin-sensitive hyperpolarization in rat gastric fundus. British Journal of Pharmacology, 109: 415-423.

5. Cetiner M \& Bennett MR (1993). Nitric oxide modulation of calciumactivated potassium channels in postganglionic neurones of avian cultured ciliary ganglia. British Journal of Pharmacology, 110: 9951002.

6. Kobzik L, Reed MB, Bredt DS \& Stamler JS (1994). Nitric oxide in skeletal muscle. Nature, 372: 546-548.

7. Ribera J, Marsal J, Casanovas A, Hukkanen M, Tarabal O \& Esquerda 
JE (1998). Nitric oxide synthase in rat neuromuscular junctions and in nerve terminals of Torpedo electric organ: its role as regulator of acetylcholine release. Journal of Neuroscience Research, 51: 90102.

8. Sakuma I, Stueher DJ, Gross SS, Nathen C \& Levi R (1988). Identification of arginine as a precursor of endothelium-derived relaxing factor. Proceedings of the National Academy of Sciences, USA, 85: 8664-8667.

9. Moncada S, Higgs A \& Furchgott R (1997). International union of pharmacology nomenclature in nitric oxide research. Pharmacological Reviews, 49: 137-142.

10. Ambiel CR \& Alves-Do-Prado W (1997). Neuromuscular facilitation and blockade induced by L-arginine and nitric oxide in the rat isolated diaphragm. General Pharmacology, 28: 789-794.

11. Silva HMV, Ambiel CR \& Alves-Do-Prado W (1999). The neuromuscular transmission fade (Wedensky inhibition) induced by L-arginine in neuromuscular preparations from rats. General Pharmacology, 32: 705-712.

12. Queiroz RN \& Alves-Do-Prado W (2001). Effects of L-arginine on the diaphragm muscle twitches elicited at different frequencies of nerve stimulation. Brazilian Journal of Medical and Biological Research, 34: 825-828.

13. Bülbring $E$ (1946). Observations on the isolated phrenic nerve diaphragm preparation of the rat. British Journal of Pharmacology, 1: 36-61.
14. Cruciol-Souza JM \& Alves-Do-Prado W (1999). Atropine and ODQ antagonize tetanic fade induced by L-arginine in cats. Brazilian Journal of Medical and Biological Research, 32: 1277-1283.

15. Van Luteren E, Moyer M \& Torres A (1995). Effect of $\mathrm{K}^{+}$channel blockade on fatigue in rat diaphragm muscle. Journal of Applied Physiology, 79: 738-747.

16. Hammarström AKM \& Gage PW (1999). Nitric oxide increases persistent sodium current in rat hippocampal neurons. Journal of Physiology, 520: 451-461.

17. Ahern GP, Hsu SF, Klyachko VA \& Jackson MB (2000). Induction of persistent sodium current by exogenous and endogenous nitric oxide. Journal of Biological Chemistry, 275: 28810-28815.

18. Renganathan M, Cummins TR, Hormuzdiar WN, Black JÁ \& Waxman SG (2000). Nitric oxide is an autocrine regulator of $\mathrm{Na}^{+}$currents in axotomized C-type DRG neurons. Journal of Neurophysiology, 83: 2431-2442.

19. Renganathan M, Cummins TR \& Waxman SG (2002). Nitric oxide blocks fast, slow and persistent $\mathrm{Na}^{+}$channels in C-type DRG neurons by S-nitrosylation. Journal of Physiology, 87: 761-775.

20. Archer SL, Huang JMC, Hampl V, Nelson DP, Shultz PJ \& Weir EK (1994). Nitric oxide and cGMP cause vasorelaxation by activation of a charybdotoxin-sensitive $\mathrm{K}^{+}$channel by cGMP-dependent protein kinase. Proceedings of the National Academy of Sciences, USA, 91: 7583-7587. 